\title{
Refutation and Introspection of Modern Intellectuals on Western Discriminatory Utterances
}

\author{
Haipeng Wang \\ School of History and Culture, Ludong University \\ Yantai 264025, Shandong, China \\ E-mail: wanghp0110@126.com
}

Received: October 13, 2011

Accepted: November 17, $2011 \quad$ Published: January 1, 2012

doi:10.5539/ach.v4n1p73

URL: http://dx.doi.org/10.5539/ach.v4n1p73

\begin{abstract}
Ever since the modern times, with successive failure of the Qing Government in wars with foreign countries, discriminatory utterances of western countries towards the Chinese nation have been overflowing gradually. These discriminatory utterances have deeply pricked the Chinese patriotic intellectuals, and further stir up their patriotic enthusiasm in saving the nation from subjugation and ensuring its survival. In the anti-imperialist patriotic movement, discriminatory utterances of modern intellectuals have exhibited obviously two trends of resistance and introspection.
\end{abstract}

Keywords: Discrimination, Utterance, Refutation, Introspection, National arousal

1. Generation and Overflow of Discriminatory Utterances of Modern Western Countries towards the Chinese Nation

After the Opium War was over, the Qing Government declined in the national power, subjected to repeated foreign aggression, and was compelled to sign a series of unequal treaties with big powers in the world which humiliated the country and forfeited its sovereignty. Compared with their previous opinions about the Chinese nation, western countries' opinions about China immediately took great change.

As early as in the Fourteenth and Fifteenth centuries, with prevalence of the book "The Travels of Marco Polo" in Europe, the Chinese nation had been a heaven on earth with "gold everywhere" in the eyes of western people, a nation full of marvelous color and western people generally were suffused with worship and envy towards the Chinese nation and the eastern civilization it represented. Within quite a long period of time afterwards, Ming Government and Qing Government carried out the strict policy of closing the country to international intercourse. Communication between Chinese people and western people was quite limited, which caused awareness of western countries of the Chinese people to still remain in a dreamy conjecture and guess in the past. It was not until 1840 when the Chinese secluded door was open to the outside world that more and more western people who came to China were able to observe China in a near distance.

Knowledge of western people in the Chinese nation has undergone a process from part to whole and from simple to complex. At the beginning of the modern times, although western people who came to China had totally different motives, they all intended to come to know about the Chinese nation with great eagerness. It didn't take a long time that they found a huge "gap" existed between the actual situation of the Chinese nation and the situation of China in their intrinsic concept. Works by western people who came to China during this period all, without exception, specially described differences between western countries and the Chinese nation and differences between the realistic China and China in their intrinsic concept. In addition, when they observed the Chinese nation, it was general that they all took great interest in the serious overflow of opium, the laggard life style of Chinese people, the mere courtesy of unnecessary and overelaborated formalities, those women with feet bound, those men wearing a long pigtail, and so on. Whenever these phenomena were mentioned, western people, all without exception, shot off their mouth, generous with their ink. Such derogatory terms as "fatuity", "ignorance", "idleness" and so on were widely used to describe the Chinese nation and Chinese people. These trends made western countries have lower evaluation on Chinese culture.

To be honest, some descriptions by western people who came to China about the Chinese nation and Chinese 
people were not totally fabricated or slandered. However, they took a part for the whole and applied this kind of utterances for all the national people, which, without doubt, was discrimination towards the Chinese nation and Chinese people. Behind all these discriminatory utterances hid their crankiness, consequentiality as well as arrogance. Of course, at that time, the number of western people who came to China was limited and their focus was usually different and their opinions were not totally identical. Especially when the knowledge of each western person was always limited, it was unlikely that they could have an overall summary about the Chinese situation.

After careful observation for almost half a century, western people who came to China had already had a relatively comprehensive and profound understanding in the Chinese people and thus, formed a relatively systematic "Chinese concept". In the mean while, western big powers held a more and more violent attitude towards the Chinese nation. By the end of the $19^{\text {th }}$ Century and the beginning of the $20^{\text {th }}$ Century, with rising and upsurging tide of imperialist in carving up the Chinese nation, discriminatory utterances of western people towards the Chinese people also attained a quite insolent degree. On October 17, 1896, a British published an article in the English journal "Zixilin Magazine", in which the British, for the first time, called Chinese people "sick man of East Asia". This was a summary of the overall image of Chinese people and also one of the most representative utterances among all the discriminatory utterances towards China.

Discriminatory utterances of western people towards the Chinese nation were caused by multiple reasons. The Chinese nation was poor and weak, suffering from insult and humiliation to the fullest extent and a low international status was the most fundamental reason for this sort of utterances. Then, western countries were deeply affected by the Christianity, which was an important reason for the "preconception" of western people in observing the Chinese nation and people who came to China. According to the Church of Christ, the place which was not shined by the light of Christianity was the darkest place in the world and the nation which was not shined by the light of Christianity was "a nation still in the darkness". Originally, western and Chinese cultures had enormous differences. Then, there is nothing strange that western people are unlikely to get to approval on the Chinese culture since they treated with Chinese culture with such prejudice, ignored diversity of the nation and otherness of its culture and saw and treated with Chinese culture with a western standard. Besides, the cultural undertaking of modern China was not greatly developed, and a large majority of the earliest journals and magazines were initiated by western people who came to China, so the right to speak was naturally controlled by western big powers, which offered convenience for prevalence and overflow of western people's discriminatory utterances towards China.

\section{Change of Modern Intellectuals' Attitude towards Western Discriminatory Utterances towards China from Refutation to Introspection}

On one hand, aggression and enslaving of western big powers in the Chinese nation made the whole nation trapped in intense national contradictions. Since the vast majority of the national people had been mounting public indignation, their emotion of exclusion was quite upsurging. On the other hand, although the Chinese nation had been frequently defeated by western "small countries", the concepts of "heavenly on the country" and "everything but mine" were still deeply rooted. It directly stimulated modern Chinese people's anti-aggression struggle that those "barbarians" which the Chinese nation had always held in contempt had gone so far as to speak rudely of the Chinese people to the eye. On balance, before the Sino-Japanese War, reaction of the Chinese people to the western discriminatory utterances was mainly refutation of traditional scholars and struggle of the common people with a lower social class, while these people had limited introspection on themselves. This was because under such a large background of extreme opposition between China and western countries, any impartial and dialectical response to western utterances would, unavoidably, be suspected as "betraying the country" and "fawning on foreign powers".

Reaction of the Chinese people to western people's discriminatory utterances had taken great changes before and after the Sino-Japanese War, and their introspection on the nation itself gradually escalated to a leading status. Causes for this change were complicated. In the first place, with daily increasing frequency in communication between Chinese and western cultures, the Chinese people had had a clear idea about differences between China and western countries and had tangible understanding in the disadvantages of the nation itself. However, general existence of a variety of problems in China made the Chinese people seem more or less unconfident enough in facing up with censure of western people. In the second place, for the past few decades, refutation of traditional scholars to western people's discriminatory utterances was almost based on the precondition that "Chinese culture was superior to western culture", and were short of a sensible analysis of both Chinese and western cultures, so they were unable to resolve the realistic problems. However, although the protest movement of the lower social-class common people's high feeling manifested the justified spirit of the national people to protect 
the national dignity, that had also brought about lots of diplomatic disputes, giving rise to many losses to China. In the third place, formation of the newly born group of intellectuals was also an important factor. Compared with the craze emotion of the common people with lower social class, the vast majority of newly born intellectuals exhibited more calmness and intelligence. Furthermore, relatively dispassionate introspection was always closely connected with exploration of the path "to save the country and the people".

Of course, modern intellectuals' understanding in some discriminatory utterances by the western people was also somewhat biased. For example, the expression "sick man of East Asia" superficially satirized emaciated appearance of Chinese people and their weak body, but actually ridiculed conserved, closed and laggard Chinese thinking and their absurd behavior under the rose. At the beginning, quite a large number of Chinese people came to understand this expression purely from its literal meaning and only came to have the awareness of its superficial meaning, but ignored more profound content behind the expression. At that time, there were quite a lot of intellectuals regarded it as an effective prescription to save the country to advocate "a military spirit", strengthen the physical exercise, build the body and improve the human species based on this biased understanding. As a result, such social trends of thought as "militarism" came to in vogue day by day. Victory of such martial predecessors as Huo Yuanjia et al in the competition in military skills with western men of unusual strength was regarded by Chinese people as a vigorous evidence of holding their head high and changing the image of "sick man of East Asia" of the Chinese people.

Liang Qichao had an extremely profound understanding in the expression "sick man of East Asia" at the very beginning. According to him, "Chinese people have been dead to all feelings for quite a long time". Thus, Liang Qichao attached great importance to "initiating the national intelligence" and gave a systematic explanation to the "New national people" thought of "initiating the national intelligence" and "educating national morality", with the expectation to arouse the self-consciousness of the Chinese people. Quite a large number of revolutionary intellectuals also emphasized moulding and educating the "new soul of the national people", and advocated using a scientific spirit to give ideological enlightenment to the people. There were also some intellectuals whose understanding in the expression "sick man of East Asia" had undergone a process of change. Lu Xun was the most typical one. Lu Xun took a sea-voyage eastward at his early years to Japan and initially selected medicine with the purpose of rescuing physical pain of the patients and building the physique of the national people. Later, he deeply experienced the foolishness and numbness of the Chinese people, and a drastic change took place in his thinking. He believed that he had to firstly secure the spirit of the national people and arouse the awareness of the people in order to really secure his own nation. Hence, he resolutely abandoned medicine and went in for arts. After the New Culture Movement (around the time of the May 4th Movement in 1919), radical new cultural intellectuals vigorously advocated treating with problems with a scientific attitude and method. At that time, introspection of the national people obviously outweighed their refutation and struggle to the foreign countries and occupied a leading status.

In one word, there are two trends of refutation and struggle among modern intellectuals for western people's discriminatory utterances. Prior to the modern times, refutation and struggle to foreign countries took a primary status and most of participants were traditional scholars and common people with a lower social class, with the struggle form directly manifested as a varieties of anti-aggression wars. Ever since the end of the $19^{\text {th }}$ Century and the beginning of the $20^{\text {th }}$ Century, introspection of the nation itself escalated to a leading status and most participants were the bourgeoisie intellectuals, with the major content of "correcting the national traits" and exploring the truth of "securing the nation and the people". Change of modern intellectuals' from mechanical refutation to profound introspection in their attitudes towards western people's discriminatory utterances has been an important manifestation of the awakening of the Chinese nation, which still has quite important enlightenment significance to us today. In face of criticism and attack of some western countries on the Chinese nation at present, we should not only have reasonable and justified refutation and struggle, but, meanwhile, also have to have the courage to face up with our own disadvantages and deficiencies and take the initiative in getting rid of those negative factors that impede development of the society. This can not only promote continuously progress of the Chinese society, but can also make it possible that western countries have no excuse to attack the Chinese nation.

\section{References}

Duan, Q. (2004). Progress of Advances-Localization of Christianity in China. The Commercial Press (in Chinese).

Gong, S. D. (1997). Exploration of Chinese Modern Culture. Beijing Normal University Press (in Chinese).

Gong, S. D. (2005). Social Reform and Cultural Orientation. Beijing Normal University Press (in Chinese). 
Huang, Y. Z. (1991). Social Transition and Traditional Customs. Taipei Youth Cultural Enterprise Co., Ltd. Li, X. S. and Yuan, Q. (2010). Autobiography of Liang Qichao. People's Publishing House (in Chinese).

Liang, J. H. (1998). Study on Evolution of Modern Chinese Undesirable Customs and Culture. Capital Normal University Press (in Chinese).

Liang, Q. C. (1994). Theory of New National People. Liaoning People's Publishing House (in Chinese).

Lin, Z. P. (1988). Idea and Symbol: Dissertation Collection of Christianity and Modern Chinese Academic Seminar. Cosmic Light Publishing House.

Liu, X. F. (1995). Morality and Speech-Encounter of Chinese Culture and Christian Culture. Shanghai Joint Press (in Chinese).

Lv, S. Q. (1985). Reasons for Chinese Officials to Oppose to Religions (1860 - 1874). Institute of Modern History Academia Sinica.

Wang, Z. X. (2004). Outline of Chinese Christian History. Shanghai Ancient Books Publishing House (in Chinese).

Zheng, D. H. and Peng, P. Y. (2008). Social Structure Change and Modern Cultural Transition. Sichuan People's Publishing House (in Chinese). 